relief so that the points to be settled can be more clearly seen.

An exhibition of apparatus and films was arranged by Dr. Wilson with the main purpose of illustrating points in the lectures. For example, the Cambridge Instrument Company showed photographs of its latest types of microphotometer, and Dr. Bradley's laboratory produced a set of powder cameras the diameters of which vary from $2.5 \mathrm{~cm}$. to $35 \mathrm{~cm}$.- a graphic demonstration of the way in which this type of camera has developed in the last twenty years.

Mr. Bunn showed some photographs illustrating the method of evaluating structure-amplitudes optically. Sir Lawrence Bragg's 'X-ray microscope', which may be said to have heralded this tendency to return to optical principles for solving crystal structures, was also on view, and was used to show diffraction by a three-dimensional grating as well as several of the effects described in Mr. Bunn's lectire.

In connexion with the papers on "Recent Developments", photographs from superlattices were exhibited; Dr. Lonsdale showed a beautiful series of prints of her 'diffuse reflexions', and Dr. Vera Daniel showed some of the photographs with which the 'side-band' effects have been studied.

The discussion on "Line Broadening" was illustrated by an exhibit by Mr. A. R. Stokes showing the broadening caused in the several ways enumerated by Dr. Wilson. In addition, Dr. D. P. Riley produced a series of photographs of coals taken with crystalreflected radiation. These photographs show a spreading of the central beam-'low-angle scattering' - that can be correlated with the actual particle-size in the specimen, as distinct from the crystal size that most X-ray measurements produce.

There were several other exhibits of general and metallurgical interest, and as a practical example of the working of an X-ray laboratory the Crystallographic Laboratory of the University was also open for inspection.

\section{BRITISH ELECTRICAL AND ALLIED INDUSTRIES RESEARCH ASSOCIATION}

T HE twenty-second annual report (E.R.A./T.331) of the British Electrical and Allied Industries Research Association summarizes the work which has been carried out during the year ended September 30,1942 , and, like its predecessor, lists by titles the various research reports which have been issued during the period. The work is reviewed under eighteen major classifications, among which, as was pointed out on the previous occasion, are again the important ones of dielectrics, cables and overhead lines, electric control apparatus, steam-power plant and condensers, magnetic materials, transformers, surge phenomena and rural electrification.

The report shows that the work of the Association is now carried on by 112 technical sections, subcommittees and panels comprised of technicians and scientific workers engaged in industry and in universities and other training institutions. Fiftyseven technical reports on a variety of subjects have been issued by the Association during the year, and fifty-one others were in an advanced stage of preparation at the end of the year. These may be divided as follows, giving, in each instance, first new reports and, secondly, reports in preparation: di- electrics, 20, 15; cables and overhead lines, 8, 4; electric control apparatus, 15, 16; steam-power plant and condensers, 2,2 ; communication interference, 3, 2 ; magnetic materials, 2, 2 ; transformers, 0,1 ; surge phenomena, 4, 3; safety problems, 0,3 ; rural electrification, 1,1 ; transformer noise, $2,2$.

The Information Bureau has been particularly active during the year, and Government and Service Departments are now making increasing use of its services. The Association's card index now contains nearly 30,000 special references, and current matter is being added at a substantial rate. The first half of the complete analytical index to the contents of E.R.A. reports, covering electrotechnical materials, has now been completed. Close co-operation has been effected with the British Standards Institution in connexion with the electrical engineering section of the Universal Decimal Classification and with the Insti. tution of Electrical Engineers in connexion with Science Abstracts.

The work of the Association has outgrown the capacity of the Perivale Laboratory in spite of the large amount of work which is still carried out by other bodies under its auspices, and this now necessitates removal of the laboratory to another site.

The E.R.A. is largely employed in finding specific answers to clearly formulated questions, and the former are of immediate value. Even more important contributions are being made by the E.R.A. in those fields in which the need for guidance is foreseen but the questions cannot yet be clearly put. It may take the industry many years to absorb a result of researches of the latter type, because this may involve a minor revolution in outlook and practice. Certain researches in hand fall definitely into this category; for example, some of those concerned with the phenomena of arcing, dielectric phenomena, properties of circuits, interference with communication circuits, surge phenomena, transformer design, magnetic materials and surface tension.

Notwithstanding the pressure of direct war work, serious fundamental research on dielectrics has been maintained. Industry in war-time has co-operated with and utilized the E.R.A. in dealing with many immediate problems affecting the successful utilization of particular insulating materials.

Of prime interest to the electricity supply industry are the long-range researches designed to increase the reliability, efficiency and safety, and heighten the performance, of plant used for the generation and distribution of electric power. The larger part of the work done falls within this category, and is linked closely with the user interest. Work on problems of electricity supply technology has been brought into increased activity and, in general, co-operation with authorjzed undertakings has been increased.

The investigation of breakdowns of plant and the devising of steps for prevention of the recurrence are the responsibility of engineers immediately concerned, but in so far as they generally involve surge phenomena, phenomena of arcing and questions of the properties of circuits, members can consult the E.R.A. Such work is not only of benefit to the member concerned but also benefits others similarly situated, and assists the investigators in establishing a true perspective as to the needs of the industry.

Continuous progress has been made in establishing liaison with all concerned with post-war reconstruction in the field of agriculture, and there has been increased appreciation of the contributions that the E.R.A. is making. 